\title{
A TREAMENT OF DOMESTIC SEWAGE AND GENERATION OF BIO SLUDGE USING NATURAL COAGULANTS
}

\author{
R. K. Jain ${ }^{1}$, Purushottam S. Dange ${ }^{2}$, Ravindra K. Lad $^{3}$ \\ ${ }^{1}$ Principal, D.Y.P.I.E.T Pimpri, Pune 18, MH, India \\ ${ }^{2}$ Research Scholar, Department of Civil Engineering, D.Y.P.I.E.T Pimpri, Pune 18, MH, India \\ ${ }^{3}$ Professor, Department of Civil Engineering, D.Y.P.I.E.T Pimpri, Pune 18, MH, India
}

\begin{abstract}
The waste generated from various human activities promotes an environmental degradation. Sewage a waste produced through human is a source of water pollution. An improper handling of sewage and waste generated from societies pollutes fresh water bodies. In Indian conditions, conventional treatments like Activated Sludge Process, Oxidation Ponds, Aerated lagoons, and Trickling filters are the most suitable treatment process to treat sewage generated in urban areas. While the land required to setting conventional treatment plant along with energy and time required is more which increases overall cost of the treatment process. To upgrade conventional treatment process and reduce cost of treatment, uses of natural coagulants are best alternative. The study is carried out to check efficiency of combinations of natural coagulants in different preparations, to treat sewage. Natural coagulants extracted from seeds of Acacia Nilotica [Babul] and Mangifera Indica [Mango] are used with different combinations to treat sewage. After laboratory analysis of treated water through primary treatment process shows around $45 \%$ and $56 \%$ of BOD and TSS removal respectively which is more than primary settling tank of conventional treatment process. Which will increases efficiency of primary treatment and reduces organic loading over secondary treatment. Due this the size of secondary unit can be reduced so area of land required to set plant can also be reduced. Use of natural coagulants will minimize time and energy required for aeration. Also sludge generated through primary treatment process will effectively used as soil stabilizer after proper composting. This study aims to reduce overall cost of sewage treatment along with recovery of plant nutrients as compost.
\end{abstract}

Keywords: Sewage, Combination of natural Coagulants, Sludge etc... ****.

\section{INTRODUCTION}

The waste generated from various human activities promotes environmental degradation. Improper handling of sewage and waste generated through societies pollutes fresh water bodies. In Indian conditions, conventional treatments like Activated Sludge Process is the most suitable treatment process to treat sewage generated. While the land required to setting conventional treatment plant along with energy and time is more which increases overall cost of treatment process. In waste water treatment chemical coagulation and flocculation treatment processes are used to overcome these problems. The chemical method has limited success in waste water treatment because of its lack of consistency in meeting discharge requirements, high costs for chemicals, handling and disposal of great volumes of sludge resulting from addition of chemicals, and numerous operating problems [11].

Coagulant extract from naturally available material like seeds of plant may be a good alternative to chemical coagulants. A natural coagulant will improve the quality of treated sewage and also recover plant nutrients in the form of sludge. Natural coagulants may be support to secondary treatment based on microbial activities, which has been badly affected by chemical coagulation.
Chun-Yang Yin [2] reviewed that plant based coagulants are cost effective as compare with chemical coagulants in water as well as waste water treatment. Hitendra Bhuptawat, et. al. [6] investigated efficiency of Moringa oleifera individually and in combination with alum for different proportions to treat waste water. Mishra M. Agarwal, et. al.[13], investigated Plantago Psyllium mucilage a low cost flocculating material able to remove suspended solids from sewage and tannery waste. The agro based materials like Moringa Oleifera (Surjana seeds); Nirmali seed (Strychnos potatorum) and Maize (Zeemays) are evaluated as natural coagulant aid with alum by Pramod Kumar Raghuwanshi, et.al. [17]. Dange P S, Lad R K [3,4] studied Mangifera Indica and Acacia Nilotica separately to see individual base impact as Natural coagulant to treat sewage. All these studies shows natural coagulants used individually or in combine with alum, In this study natural coagulants are used in combination with different proportions.

In this study, the attempt has been made that quality of treated sewage, sludge generated through primary treatment can be improved by natural coagulation and cost of overall treatment of sewage can be reduced in terms of less land required to set treatment plant, construction cost and reduction in energy and time required to treat sewage. 


\section{Materials and MethodOLOGY}

\subsection{Materials}

Acacia Nilotica [Babul] fruits were collected from village Chikhali, Tal. \& Dist. Osmanabad and Mangifera Indica [Alphonoso Mango] fruits are purchased from local market and seeds of mango used for this study.

\subsection{Methodology}

The procedural method to be followed in order to ultimately find out the optimum dose of the coagulant used, to remove the turbidity of raw water is shown in the following flow diagram.

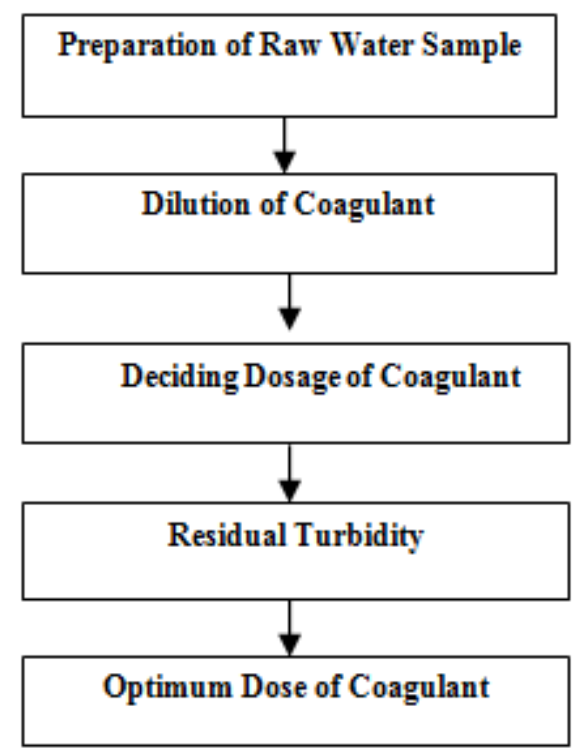

Fig - 1: A Flow Diagram of Research Approach

For the pilot plant study, first sewage treatment units were designed for sewage discharge of 1 Mld and then units were fabricated with scale of 25 .

Table 1 shows sizes of designed and pilot plant model units.

Table -1: Sizes of Designed and Pilot Plant Model Units

\begin{tabular}{|l|l|l|l|l|}
\hline $\begin{array}{l}\text { Name of } \\
\text { Unit }\end{array}$ & $\begin{array}{l}\text { Sizes of Designed } \\
\text { Units }\end{array}$ & $\begin{array}{l}\text { Sizes of Units } \\
\text { For 1 Mld } \\
\text { discharge (mm) }\end{array}$ & $\begin{array}{l}\text { Reduced } \begin{array}{l}\text { Scale of 25 for pilot } \\
\text { plant model }\end{array} \\
\text { pom) }\end{array}$ \\
\hline $\begin{array}{l}\text { Flash } \\
\text { Mixer }\end{array}$ & 1500 & 1800 & 60 & 80 \\
\hline $\begin{array}{l}\text { Clari- } \\
\text { flocculator }\end{array}$ & 3000 & 6000 & 120 & 240 \\
\hline
\end{tabular}

The coagulating constituents were extracted from natural materials as Dried Mangifera Indica seeds were broken to separate out hard upper cover. Mangifera Indica seeds soft inner portion and Acacia nilotica seeds were grinded to a fine powder and stored in air tight container separately. 10 grams of powdered materials were mixed in distilled water using magnetic stirrer with a speed of $100 \mathrm{rpm}$ for 15 minutes to prepare $1000 \mathrm{ml}$ of solution. The solution was allowed to settle suspended solids. Then supernatant pass through Whatman filter paper no 40 and the filtered liquid collected as extracted natural coagulant, which has been used for further study work.

1. The samples were collected twice in a week from sewage treatment plant located in Pimpri- Chichwad Municipal Corporation Area and studied through pilot plant model.

2. Optimum dosages for natural coagulants in combination with different proportions are determined by Jar test for different turbidity range.

Table 2 shows different turbidity range with dosage of natural coagulants.

Table 2: Dosage of Natural Coagulants for Different Turbidity

\begin{tabular}{|l|l|l|l|l|l|l|}
\hline $\begin{array}{l}\text { Sr. } \\
\text { No. }\end{array}$ & $\begin{array}{l}\text { Type of } \\
\text { Turbidity }\end{array}$ & $\begin{array}{l}\text { Range of } \\
\text { Turbidity, } \\
\text { NTU }\end{array}$ & \multicolumn{5}{|l|}{ Dosage in ml/lit } \\
\hline 1 & $\begin{array}{l}\text { Low } \\
\text { Turbidity }\end{array}$ & $50-100$ & 4 & 8 & 12 & 16 \\
\hline 2 & $\begin{array}{l}\text { Medium } \\
\text { Turbidity }\end{array}$ & $100-150$ & 8 & 12 & 16 & 20 \\
\hline 3 & $\begin{array}{l}\text { High } \\
\text { Turbidity }\end{array}$ & $\begin{array}{l}\text { More than } \\
150 \text { NTU }\end{array}$ & 12 & 16 & 20 & 24 \\
\hline
\end{tabular}

The natural coagulant, Acacia Nilotica [AN] and Mangifera Indica $[\mathrm{MI}]$ were used in combinations with different proportions (Refer Table 3).

Table - 3: Proportions of Coagulants

\begin{tabular}{|l|l|}
\hline Particulars & Proportion \\
\hline$[\mathrm{MI}: \mathrm{AN}]$ & $80: 20 \%$ \\
\hline$[\mathrm{MI}: \mathrm{AN}]$ & $60: 40 \%$ \\
\hline$[\mathrm{MI}: \mathrm{AN}]$ & $50: 50 \%$ \\
\hline$[\mathrm{MI}: \mathrm{AN}]$ & $40: 60 \%$ \\
\hline$[\mathrm{MI}: \mathrm{AN}]$ & $20: 80 \%$ \\
\hline
\end{tabular}

The Jar test for finding optimum dosage was carried out with rapid mixing about $100 \mathrm{rpm}$ for 1 minute and slow mixing about $30 \mathrm{rpm}$ for 30 minutes. Residual turbidity for different combinations of coagulant dosages was measured in the interval of 120 and 720 minutes. A Graph used to determine optimum dosage shows relation between residual turbidity and optimum dosage for different turbidity range

Figure 2 shows for combination of $\mathrm{MI}$ and $\mathrm{AN}$ in proportion of [80:20] as natural coagulant for low turbidity, similarly other graphs were prepared for the determination of optimum dosages.

The optimum dosage for natural coagulants, alum and their combinations with different turbidity are shown in Table 4. 


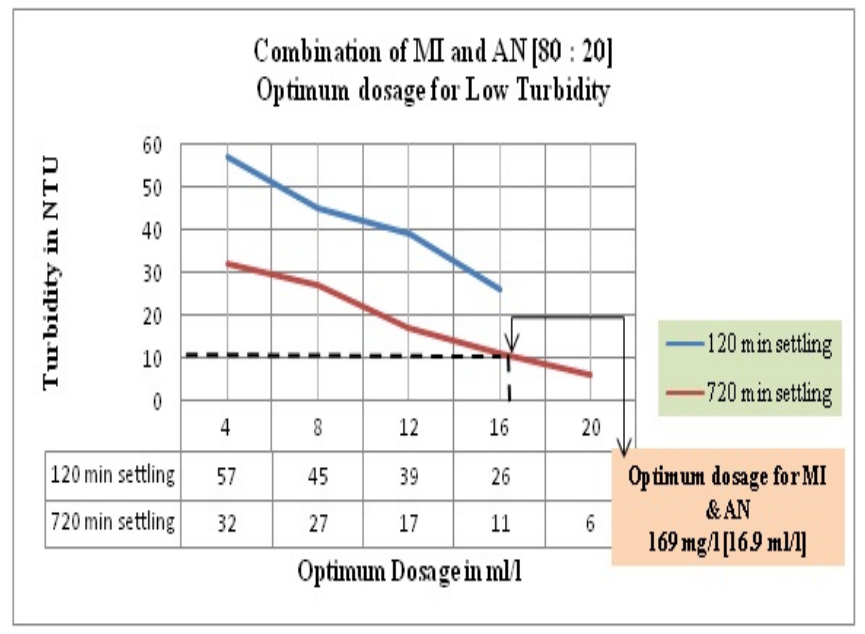

Fig -2: Optimum dosage for MI and AN combination in proportion of [80: 20] \%

Table - 4: Optimum dosages for Acacia Nilotica [AN] and Combination of AN and Alum [A]

\begin{tabular}{|l|l|l|l|l|}
\hline \multirow{2}{*}{$\begin{array}{l}\text { Coagulant } \\
\text { particulars }\end{array}$} & \multirow{2}{*}{$\begin{array}{l}\text { Proportion } \\
\%\end{array}$} & \multicolumn{3}{l}{$\begin{array}{l}\text { Optimum } / 1 \\
\text { mg } /\end{array}$} \\
\cline { 3 - 5 } & & Lor turbidity range) & Med. & High \\
\hline$[\mathrm{MI}: \mathrm{AN}]$ & {$[80: 20]$} & 169 & 191 & 198 \\
\hline$[\mathrm{MI}: \mathrm{AN}]$ & {$[60: 40]$} & 171 & 194 & 200 \\
\hline$[\mathrm{MI}: \mathrm{AN}]$ & {$[50: 50]$} & 172 & 196 & 203 \\
\hline$[\mathrm{MI}: \mathrm{AN}]$ & {$[40: 60]$} & 175 & 198 & 205 \\
\hline$[\mathrm{MI}: \mathrm{AN}]$ & {$[20: 80]$} & 178 & 201 & 209 \\
\hline
\end{tabular}

From Table 4 it is observed that:

1. For the combinations of natural Coagulants as [80:20, 60:40 and 50:50] \% sample residual turbidity is in the range of $10 \mathrm{NTU}$ after 720 minutes settling.

2. The sewage samples were collected from Sewage Treatment Plants located in the vicinity of Pimpri Chinchwad Municipal Corporation. Laboratory study model is consists of only Flash mixer and Clariflocculator; so sewage samples are collected from inlet of PST [Primary Sedimentation Tank] after screening and grit removal through Screen and Grit Chamber.

3. The collected sewage was treated through pilot scale model using natural coagulants. Sewage samples are treated through laboratory study model; In flash mixer sample with optimum dose determined earlier as per turbidity range mixed rapidly at the rate of $100 \mathrm{rpm}$ for 1 minute so that mix the coagulant throughout the sample.

From flash mixer sewage water sample passed in Clariflocculator where sample is stirring at a speed of 10 rpm and continue mixing for 30 mins. This slower mixing speed helps to promote for floc formation by enhancing particle collisions, and formed floc settle at bottom of tank. The supernatant is collected and used for further laboratory analysis
The laboratory analysis of treated sewage was carried out for the determination of concentration of parameters like $\mathrm{pH}, \mathrm{DO}, \mathrm{TSS}, \mathrm{BOD}$ and COD.

Also, the laboratory analysis of sludge was carried out for the determination of concentration of parameters like Conductivity, $\mathrm{N}, \mathrm{P}, \mathrm{K}, \mathrm{pH}$, etc.

\section{MODEL APPLICATIONS, RESULTS AND DISCUSSIONS}

Treated sewage through clariflocculator was analyzed in laboratory to check quality in terms of parameters like TSS, BOD and COD and the results of the same are shown in Table 5.

Table - 5: Summary of the quality of sewage after clariflocculator using AN and different percentage of AN \&

\begin{tabular}{|c|c|c|c|c|}
\hline \multirow{2}{*}{$\begin{array}{l}\text { Coagulant } \\
\text { particulars } \\
\& \text { their } \\
\text { Proportion }\end{array}$} & \multirow{2}{*}{ Value } & \multicolumn{3}{|c|}{$\%$ Removal } \\
\hline & & TSS & BOD & COD \\
\hline \multirow{2}{*}{$\begin{array}{l}{[\mathrm{AN}: \mathrm{MI}]} \\
{[80: 20]}\end{array}$} & Range & $\begin{array}{l}49.61 \text { to } \\
58.50\end{array}$ & $\begin{array}{l}41.20 \text { to } \\
49.80\end{array}$ & $\begin{array}{l}49.50 \text { to } \\
62.60\end{array}$ \\
\hline & Average & 54.55 & 45.80 & 56.85 \\
\hline \multirow{2}{*}{$\begin{array}{l}{[\mathrm{AN}: \mathrm{MI}]} \\
{[60: 40]}\end{array}$} & Range & $\begin{array}{l}48.90 \text { to } \\
56 . .35\end{array}$ & $\begin{array}{l}40.70 \text { to } \\
49.00\end{array}$ & $\begin{array}{l}48.65 \text { to } \\
59.15\end{array}$ \\
\hline & Average & 53.05 & 44.65 & 52.75 \\
\hline \multirow{2}{*}{$\begin{array}{l}{[\mathrm{AN}: \mathrm{MI}]} \\
{[50: 50]}\end{array}$} & Range & $\begin{array}{l}48.25 \text { to } \\
55.30\end{array}$ & $\begin{array}{l}39.27 \text { to } \\
47.50\end{array}$ & $\begin{array}{l}47.50 \text { to } \\
56.09\end{array}$ \\
\hline & Average & 52.60 & 43.60 & 52.85 \\
\hline \multirow{2}{*}{$\begin{array}{l}{[\mathrm{AN}: \mathrm{MI}]} \\
{[40: 60]}\end{array}$} & Range & $\begin{array}{l}46.98 \text { to } \\
53.90\end{array}$ & $\begin{array}{l}38.14 \text { to } \\
45.72\end{array}$ & $\begin{array}{l}47.00 \text { to } \\
53.89\end{array}$ \\
\hline & Average & 50.50 & 42.85 & 52.60 \\
\hline \multirow{2}{*}{$\begin{array}{l}{[\mathrm{AN}: \mathrm{MI}]} \\
{[20: 80]}\end{array}$} & Range & $\begin{array}{l}46.65 \text { to } \\
52.80\end{array}$ & $\begin{array}{l}37.86 \text { to } \\
43.90\end{array}$ & $\begin{array}{l}45.67 \text { to } \\
51.39\end{array}$ \\
\hline & Average & 51.80 & 42.90 & 49.25 \\
\hline
\end{tabular}

\section{From Table 5 it is observed that:}

- $\quad$ By using AN with MI [80:20] \% as Coagulant, average TSS, BOD and COD removal efficiency is 54.55, 45.80 and $56.85 \%$ respectively from sewage.

- $\quad$ By using AN with MI [60:40] \% as Coagulant, average TSS, BOD and COD removal efficiency is 53.05, 44.65 and $52.75 \%$ respectively from sewage.

- $\quad$ By using AN with MI [50:50] \% as Coagulant, average TSS, BOD and COD removal efficiency is 52.60, 43.60 and $52.85 \%$ respectively from sewage.

- $\quad$ By using AN with MI [40:60] \% as Coagulant, average TSS, BOD and COD removal efficiency is 50.50, 42.85 and $52.60 \%$ respectively from sewage.

- $\quad$ By using AN with MI [20:80] \% as Coagulant, average TSS, BOD and COD removal efficiency is 51.80, 42.90 and $49.25 \%$ respectively from sewage. 
For combination of MI and AN in proportion [50:50] $\%$, the sludge from clariflocculator was collected for the determination of concentration of parameters $\mathrm{N}, \mathrm{P}, \mathrm{K}$, and $\mathrm{pH}$ and the results of the same are shown in Table No. 7.

Table - 7: Summary of the quality of Sludge after clariflocculator using AN: MI [50:50] as Natural coagulant

\begin{tabular}{|l|l|l|}
\hline $\begin{array}{l}\text { Sr. } \\
\text { No. }\end{array}$ & Particular & Concentration \\
\hline 1 & Total nitrogen $[\mathrm{N}]$ & 0.30 to $0.49 \%$ \\
\hline 2 & Phosphates $\left[\mathrm{P}_{2} \mathrm{O}_{5}\right]$ & 0.20 to $0.45 \%$ \\
\hline 3 & Potash $\left[\mathrm{K}_{2} \mathrm{O}\right]$ & 2.66 to $3.04 \%$ \\
\hline 4 & pH & 6.20 to 7.28 \\
\hline
\end{tabular}

From Table 7 it is observed that:

- $\quad$ By using AN with MI [50:50] \% as Coagulant, sludge generated through clarifloculator contains concentration of Total nitrogen $[\mathrm{N}]$ around 0.30 to $0.49 \%$.

- $\quad$ By using AN with MI [50:50] \% as Coagulant, sludge generated through clarifloculator contains concentration of Phosphates $\left[\mathrm{P}_{2} \mathrm{O}_{5}\right]$ around 0.20 to $0.45 \%$.

- By using AN with MI [50:50] \%bvas Coagulant, sludge generated through clarifloculator contains concentration of Potash $\left[\mathrm{K}_{2} \mathrm{O}\right]$ around 2.66 to $3.04 \%$.

- $\quad$ By using AN with MI [50:50] \% as Coagulant, $\mathrm{pH}$ of sludge generated through clarifloculator is in the range of 6.20 to 7.28 .

\section{CONCLUSION}

From the study it is concluded that

- TSS and BOD removal efficiency is increased due to combined effect of natural coagulants.

- As quality of effluent from primary process is improved by natural coagulation than conventional treatment process, TSS and BOD loadings over secondary units are reduced. So the sizes of units, time of treatment and energy required to aeration reduced.

- $\quad$ By using Acasia Nilotica and Mangifera indica [80:20] shows higher removal of TSS, and BOD which is around $54.55 \% \& 45.80 \%$ respectively and removal of TSS and BOD which is less around $51.80 \%$ \& $42.99 \%$ respectively by using Acasia Nilotica and Mangifera indica [20:80]. Both cases show better results than conventional treatment process.

- The constituents found in sludge are Total nitrogen [N] from 0.30 to $0.49 \%$, Phosphates $\left[\mathrm{P}_{2} \mathrm{O}_{5}\right]$ from 0.20 to $0.45 \%$ \& Potash $\left[\mathrm{K}_{2} \mathrm{O}\right]$ from 2.66 to $3.04 \%$. Sludge generated after clariflocculator by using AN with MI [50:50] \% as a natural coagulant will be a good manure after composting.

- The use of AN and MI in combination is best option to treat sewage.

- The rural economy will improve as coagulants are based on plants.

\section{ACKNOWLEDGEMENTS}

We would like to thank Mr. Sanjay Kulkarni, Executive Engineer (Environment), PCMC, Pimpri, Pune for kind support for allowing to collect untreated sewage sample from inlet of various Sewage Treatment Plant of PCMC, Pimpri, Pune.

\section{REFERENCES:}

[1] Chee Yang The, Ta Yeong Wu, (2014). "Optimization of agro-industrial wastewater treatment using unmodified rice starch as a natural coagulant." Industrial Crops and Products ,56, 1726.

[2] Chun-Yang Yin (2010). "Emerging usage of plant based coagulants for water and waste water treatment." Process Biochemistry, 45, 1437-1444.

[3] Dange P S, Lad R K (2015). "Upgrading Conventional Sewage Treatment Process by Using Mangifera Indica." International Journal for Scientific Research and Development, 3 (2), 15841588.

[4] Dange P S, Lad R K (2015). "A Treatment of Sewage using Natural Coagulant." International Journal of Emerging Technologies and Applications in Engineering, Technology and Sciences, 058 - 064.

[5] Heber M. de Paula, Marina Sangoi de Oliveira Ilha, Leonardo S. Andrade, (2014). Concrete Plant Wastewater Treatment Process By Coagulation Combining Aluminum Sulfate and Moringa Oleifera Powder, Journal of Cleaner Production, article in press.

[6] Hitendra Bhuptawat, G K Folkard, Sanjeev Chaudhari (2007). "Innovative physic-chemical treatment of waste water incorporating Moringa Oleifera seed coagulant." Journal of Hazardous Materials, 142,477-482.

[7] Ibrahim M. Ismail , Ahmed S. Fawzy Nabil M. Abdel-Monem , Mahmoud H. Mahmoud , Mohamed A. El-Halwan, (2012), “ Combined coagulation flocculation pre treatment unit for municipal wastewater" Journal of Advanced Research, 3, 331336

[8] J. Roussy, P. Philippe Chastellan, M. Van Vooren, E. Guibal, (2005), "Treatment of ink containing wastewater by coagulation/flocculation using biopolymers." Water SA 31 (3) 369-376.

[9] Kevin J Forley and Francols M M Morel (1986). "Role of coagulation in the kinetics of Sedimentation." Environmental Science Technology, 20, 187-195.

[10] Mariraj Mohan S. (2014). "Use of naturalized coagulants in removing laundry waste surfactant using various unit processes in lab-scale." Journal of Environmental Management, 136, 103-111.

[11] Metcalf \& Eddy, (2004). Wastewater Engineering Treatment and Reuse, McGraw-Hill Education (India) Private Limited, New Delhi. 
[12] Meyssami B, A B Kasaeian (2005). "Use of coagulants in treatment of Olive oil Waste water model solutions by induced air flotation." Bioresource Technology 96.

[13] Mishra A, M Agarwal, M Bajpai, S Rajani, R P Mishra , (2006). "Plantago Psyllium mucilage for sewage and tannery effluent treatment." Iranian Polymer Journal, 11,6.

[14] Monika Agarwal Rajini Srinivasan, Anuradha Mishra (2001). "Study on Flocculation Efficiency of Okra Gum in sewage wastewater." Macromolecular Materials and Engineering, 286,560-563.

[15] Muyibi, S.A., Alfugara, A.M.S., (2003). "Treatment of surface water with Moringa oleifera seed extract and alum - a comparative study using pilot scale water treatment plant." International Journal of Environmental Studies, 60 (6), 617-626.

[16] Nurudeen A Oladoja, Yekini D Aliu (2009). "Snail Shell as coagulant aid in the alum precipitation of malachite green from aqua system." Journal of Hazardous Materials, 164, 1496-1502.

[17] Pramod Kumar Raghuwanshi, Monika Mandloi, Arvind J. Sharma, Hanumant S. Malviya, Sanjeev Chaudhari, (2002). "Improving Filtrate Quality using Agrobased Materials as Coagulant Aid." Water Quality Research Journal, 37(4), 745-756.

[18] S.A.Muyibi, L.M. Evison, (1995) “Optimizing physical parameters affecting coagulation of turbid water with Moringa oleifera seeds." Water Res. 29 2689-2695.

[19] S. Bhatia, Z. Othman, A.L. Ahmand, (2007), "Coagulation flocculation process for POME treatment using moringa oleifera seed extract: optimization studies." Chemical Engineering Journal, 133 (1) 205-212.

[20] Syafalni, Han Khim Lim, Norli Ismail, Ismail Abustan (2012). "Treatment of landfill leachate by using Lateritic soil as natural Coagulant." Journal of Environmental Management, 112,353-359.

[21] Y. Chen, S. Liu, G. Wang, (2007), "A kinetic investigation of cationic starch adsorption and flocculation in kaolin suspension." Chemical Engineering Journal. 133 (1-3) 325-333s.

[22] Z. Dymaczewski, E.S. Kempa, M.M. Sozanski, (1997), "Coagulation as a structure forming separation process in water and wastewater treatment." Water Science and Technology, 36 (4) 25-32.

\section{BIOGRAPHIES}

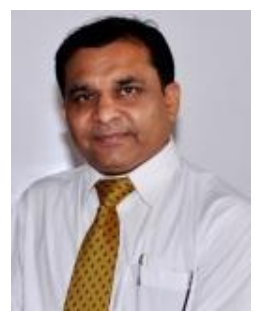

Dr. R. K. Jain, Principal, Dr. D.Y. Patil Institute of Engg. \& Tech., Pimpri, Pune. Has more than 20 years of teaching experience. Authored three technical books in the field of Civil Engineering and has contributed more than 25 technical papers on various topics at national and international seminars and

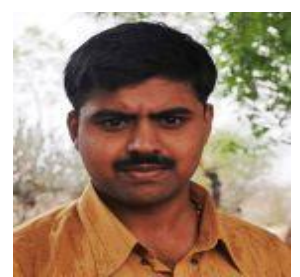

Mr. P. S. Dange, Research Scholar \& Asst. Professor, Dr. D.Y. Patil Institute of Engg. \& Tech., Pimpri, Pune. Published 02 Research papers in National /International conference and also attended more than 05 workshops and also have the experience of Organized 2 workshops.

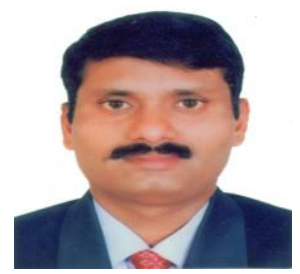

Dr. R. K. Lad, Professor, Department of Civil Engineering, Padmashree Dr. D.Y. Patil Institute of Engg. \& Tech., Pimpri, Pune. Having 13 years of teaching and 9 years of professional experience. Authored five technical books in the field of Civil Engineering and has contributed more than 15 technical papers on various topics at national and international conferences/in journals. Worked at higher level in teaching as Principal, Dean Engineering and in an industry as Senior Environmental Engineer and Project Manager.

conferences. 